\title{
Apoptotic Cells in the Human Endometrium and Placental Villi: Pitfalls in Applying the TUNEL Method
}

\author{
Masanori YASUdA $^{1}$, Shinobu UMEMURA ${ }^{1}$, R. Yoshiyuki OSAMURA ${ }^{1}$, Takiko KenJO ${ }^{2}$ and \\ Yutaka TSUTSUMI ${ }^{1}$ \\ Departments of Pathology ${ }^{1}$ and Gynecology and Obstetrics ${ }^{2}$, Tokai University School of Medicine, Isehara, Japan \\ Received January 31, 1995
}

\begin{abstract}
Summary. Apoptotic cells were histochemically demonstrated by the TdT-mediated biotinylated dUTP nick end-labeling (TUNEL) method in formalin-fixed and paraffin-embedded sections of the human endometrium and placental villi. In 53 endometrial biopsy specimens, labeled nuclei were identified in 16 samples showing a desquamating change, associated with menstruation, functional bleeding or adenocarcinoma. Cells in the normal proliferative and secretory phases were unlabeled. The labeled nuclei in the gland and stroma corresponded well to the so-called apoptotic bodies. Placental tissues at various stages of gestation were obtained by spontaneous abortion, intrauterine fetal death or normal delivery. Syncytiotrophoblastic cells in an early gestational stage (7-12 weeks) and in the term placenta were focally labeled, and the labeled cells possessed pyknotic nuclei and densely eosinophilic cytoplasm. In the early gestational chorionic villi with marked hydropic degeneration or in hydatidiform mole, the stromal cells were frequently labeled. Villous cells in coagulation necrosis (infarction) also revealed strong signals. The apoptotic bodies were not recognizable histologically in these labeled villi. The placenta at the 20th to 33rd week of gestation lacked labeling. From a technical point of view, it should be noted that cells in the foci showing ischemia or coagulation necrosis were labeled positively.
\end{abstract}

Apoptosis defined as energy-dependent programmed cell death is biochemically characterized by DNA fragmentation. Microscopically, apoptosis is associated with a peculiar nuclear change ultimately forming apoptotic bodies. Apoptosis, a physiological process in the control of cell kinetics and for the extinction of forbidden lymphocyte clones in the thymic cortex, is known to be induced by various pathological stimuli such as irradiation and heat (KERR et al., 1972; BUJA et al., 1993; CARSON and RIBEIRO, 1993; WILLIAMS and SMITH, 1993).
The terminal deoxynucleotidyl transferase (TdT)mediated biotinylated dUTP nick end-labeling (TUNEL) method was developed by GAVRIELI et al. (1992) for the histochemical demonstration of apoptotic cells in tissue sections, including routinely prepared paraffinembedded specimens. This technique, theoretically dependent upon the presence of fragmented DNA in the affected nuclei, has so far been applied to a variety of normal and pathological tissues (ANSARI et al., 1993; GORCZYCA et al., 1993; GolD et al., 1994; KASAGI et al., 1994; SAKURAGI et al., 1994).

In the present histochemical study, we tried to identify apoptotic cells in normal and pathological human endometrium and placenta. It should be carefully noted that the nuclei in areas of ischemia or necrosis (infarction) were also positively labeled by this sequence. Such a positive reaction is particularly precautious when human pathological tissues are used for the evaluation of apoptosis.

\section{MATERIALS AND METHODS}

\section{Tissue specimens}

Endometrial biopsy samples were obtained form 53 females aged 24-69 years, all subjects visiting the outpatient clinic for the evaluation of infertility or functional bleeding. In every case, clinical information on the menstrual cycle and hormone therapy was reviewed before making the final histopathological diagnosis. The diagnoses were as follows: normal proliferative phase (8 cases); normal secretory phase (12 early cases, 5 mid and 9 late); menstrual phase (13th postovulatory $=$ premenstrual day or later, 4 cases); abnormally desquamating endometrium (with proliferative features, 5 cases; with secretory features, 1 case; with cystic glandular hyperplasia, 3 cases; and 


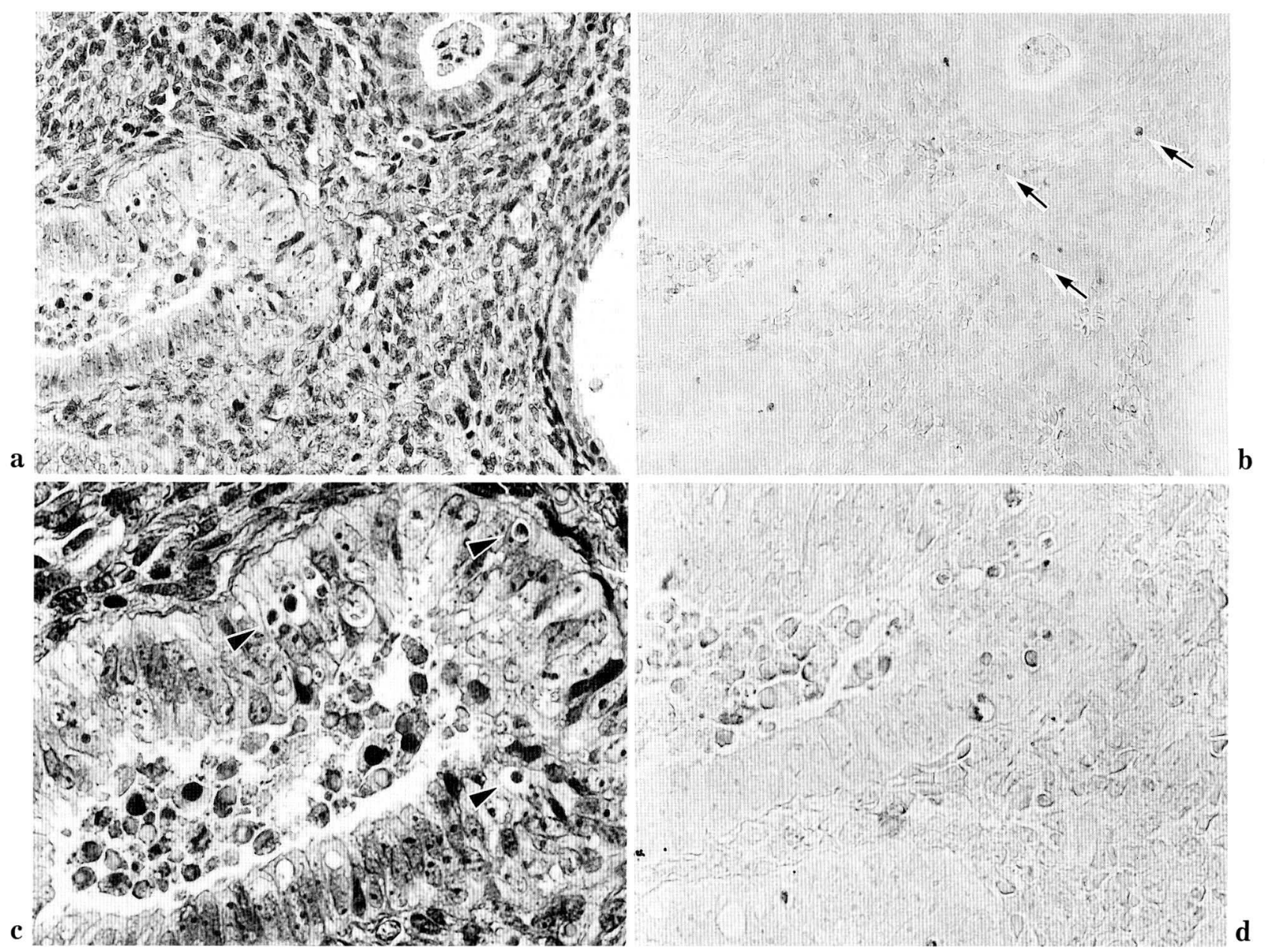

Fig. 1 a-d. TUNEL-positive nuclei scattered in the desquamating endometrium showing cystic glandular hyperplasia (49-year-old female). Both the proliferative-type glandular epithelium and the stromal cells (arrows) are labeled. The bottom panels (c, d) demonstrate high-power views of the plands. A cluster of detached epithelial cells within the lumen are also labeled. Note apoptotic bodies indicated by the arrowheads. a and c: Hematoxylin and eosin staining, $\mathrm{b}$ and $\mathrm{d}$ : the TUNEL method. $\mathrm{a}, \mathrm{b}: \times 300, \mathrm{c}, \mathrm{d}: \times 600$

with deciduoid stromal reaction, 1 case); abnormal endometrium without desquamating change (cystic glandular hyperplasia, 2 cases; deciduoid stromal reaction, 1 case); and endometrial adenocarcinoma (2 cases). Unbuffered $10 \%$ formalin-fixed and paraffin-embedded step sections were prepared. A part of 10 representative specimens were snap-frozen. Frozen sections were prepared on a cryostat, fixed in buffered $4 \%$ paraformaldehyde for $10 \mathrm{~min}$, and processed for the TUNEL sequence.

A total of 27 placental tissues obtained either by spontaneous abortion (7-12 weeks, the first trimester, of gestation: 11 cases), at the time of autopsy of intrauterinely dead fetuses (20-33 weeks, the second and third trimesters: 11 cases), or by normal delivery
(39-41 weeks, the term: 5 cases) were routinely prepared for consecutive paraffin sectioning. The age of the mothers ranged from 24 to 43 years. Chorionic villi in the first trimester often revealed varying degrees of hydropic degeneration. Focal necrosis or infarction was not rarely observed in the first trimester and term materials. Nine curettage specimens of hydatidiform mole, frequently associated with foci of necrosis, were also examined.

\section{Histochemistry}

The TUNEL method was performed according to the original description by GAVRIELI et al. (1992). Minor modification included the addition of $1 \%$ gelatin in the final reaction mixture. For the staining using 


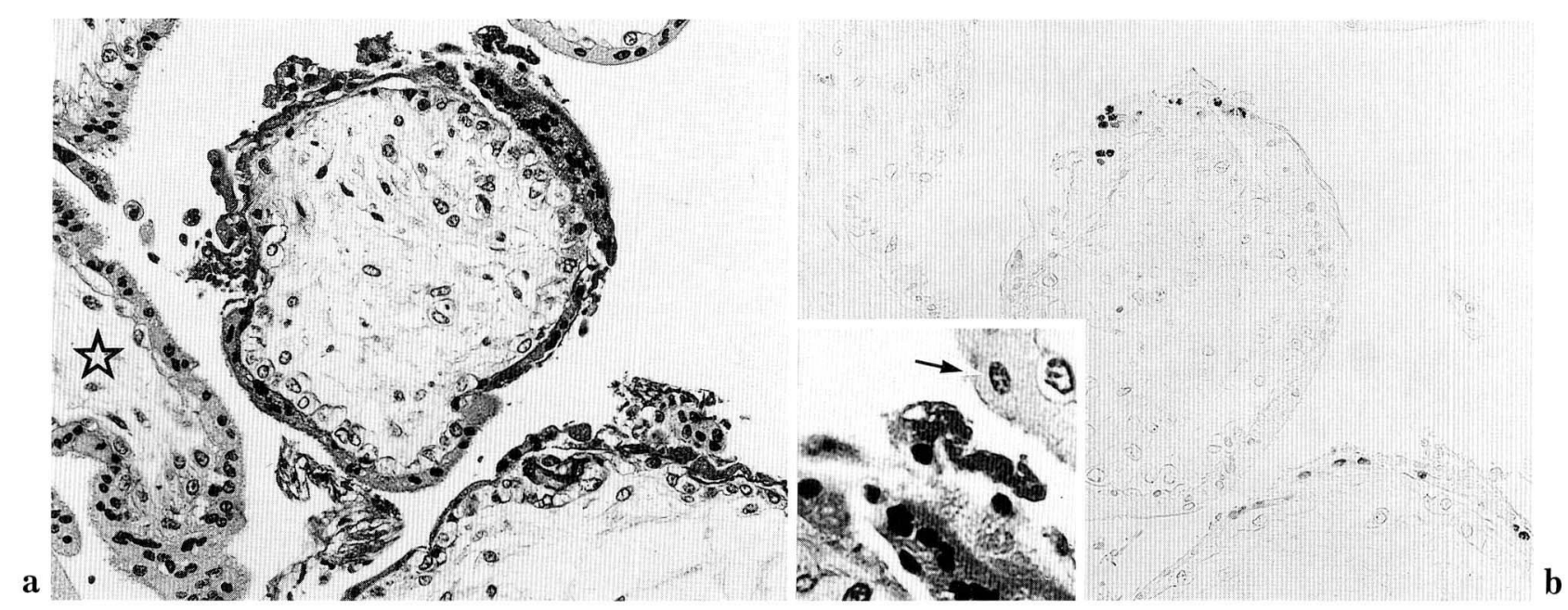

Fig. 2 a and b. TUNEL positivity seen in aborted 8-week-old chorionic villi (32-year-old female). The labeled syncytiotrophoblasts possess pyknotic nuclei and a deeply eosinophilic cytoplasm (see the inset). The attachment of cellular debris and fibrin is observed on the positively decorated villi. The star mark indicates a normal-looking and negatively labeled villus. The arrow in the inset demonstrates a high-power view of a normal nucleus of a syncytiotrophoblastic cell in an adjacent villus. a: Hematoxylin and eosin staining, b: TUNEL method. a, b: $\times 200$, inset: $\times 480$

frozen sections, proteinase K pretreatment was omitted. TdT was obtained from the Boehringer Mannheim Biochemica, Mannheim, Germany. The nuclei were counterstained with 5\% methyl green buffered by $0.1 \mathrm{M}$ Veronal acetate at $\mathrm{pH}$ 4.0. Consecutive sections were compared with hematoxylin and eosin staining.

\section{RESULTS}

\section{Endometrium}

Of 53 biopsy specimens examined, 16 showed positive nick end-labeling in the nucleus. All positive specimens revealed features of desquamation (dissociation of the glands and crumbling of the stromal cells) in either the glandular epithelial cells, stromal cells or both. The diagnoses included menstruation, functional bleeding and adenocarcinoma. The positive signals were sporadically seen within the desquamative area, and corresponded, without exception, to the apoptotic bodies in the hematoxylin and eosin preparation. Non-desquamating endometrial tissue specimens, including those with abnormal features such as cystic glandular hyperplasia or deciduoid stromal reaction, lacked signals. Figure 1 demonstrates the positive labeling of epithelial and stromal cells in cystic glandular hyperplasia (an example of functional bleeding due to an anovulatory cycle).

The nick end-labeling pattern and cell number in the comparative paraffin and frozen sections were within equal ranges.

\section{Placenta}

Clusters of syncytiotrophoblastic nuclei were positively labeled in all the first trimester placenta. When compared with the hematoxylin and eosin preparation, the labeled cells possessed highly pyknotic nuclei and densely eosinophilic cytoplasm (Fig. 2). Fibrinous exudation and cellular debris were frequently recognized on the surface of these cells. A similar nuclear labeling pattern of syncytiotrophoblasts was also focally seen in all the specimens of hydatidiform mole and in four of the five term placentas. In the second and third trimesters (20-33 weeks of gestation), there was no labeling.

The chorionic villi in the first trimester occasionally showed marked hydropic degeneration. In two cases, mildly pyknotic nuclei of the stromal cells in the hydropic villi were labeled focally (Fig. 3). The stromal cells were also unevenly labeled in all the specimens of hydatidiform mole. One characteristic was the strongly positive reaction in the chorionic villi (in the early gestation, in hydatidiform mole, or at term) showing apparent coagulation necrosis or anemic infarction (Fig. 4).

Features of apoptotic bodies were hardly identified in any of these consecutive hematoxylin and eosin stained chorionic villi. 


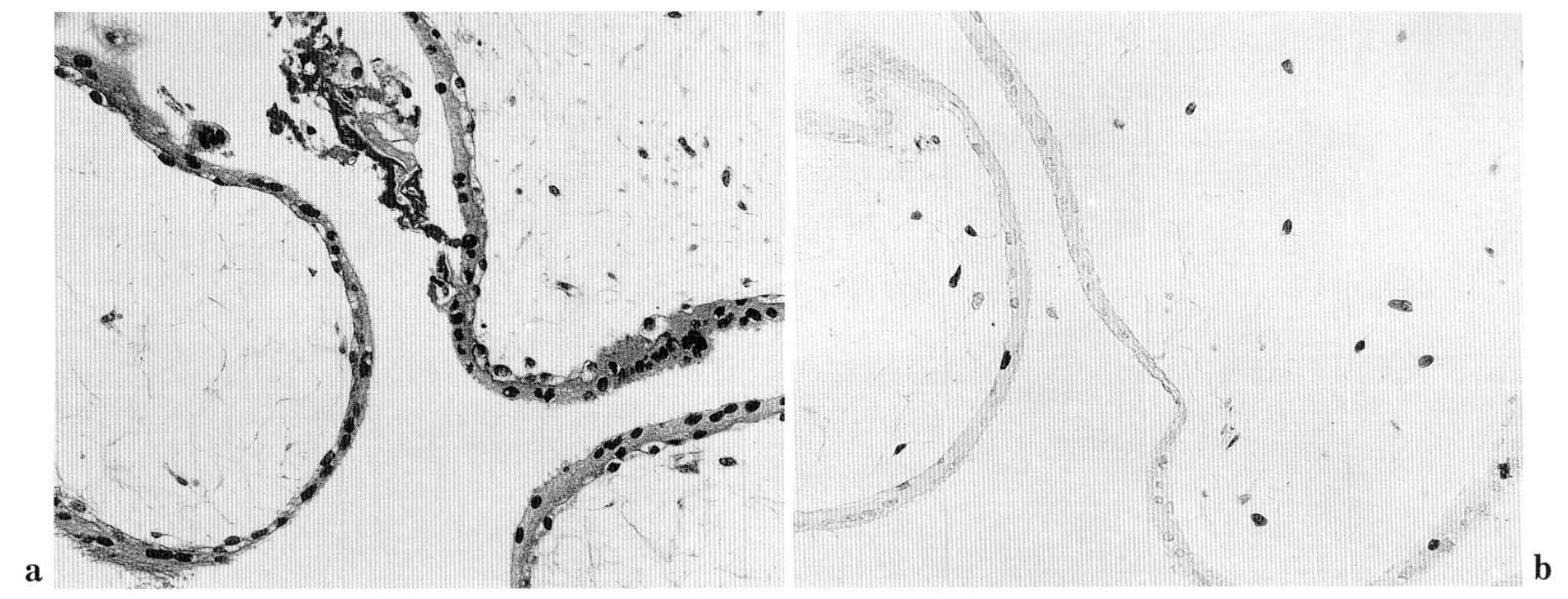

Fig. 3 a and b. TUNEL positivity in aborted 9-week-old chorionic villi with marked hydropic degeneration (34-year-old female). In addition to a few trophoblasts, fibroblastic cells in the edematous stroma are positively labeled. The nuclei are mildly pyknotic. A similar phenomenon is also observed in hydatidiform mole. a: Hematoxylin and eosin staining, b: TUNEL method. a, b: $\times 200$
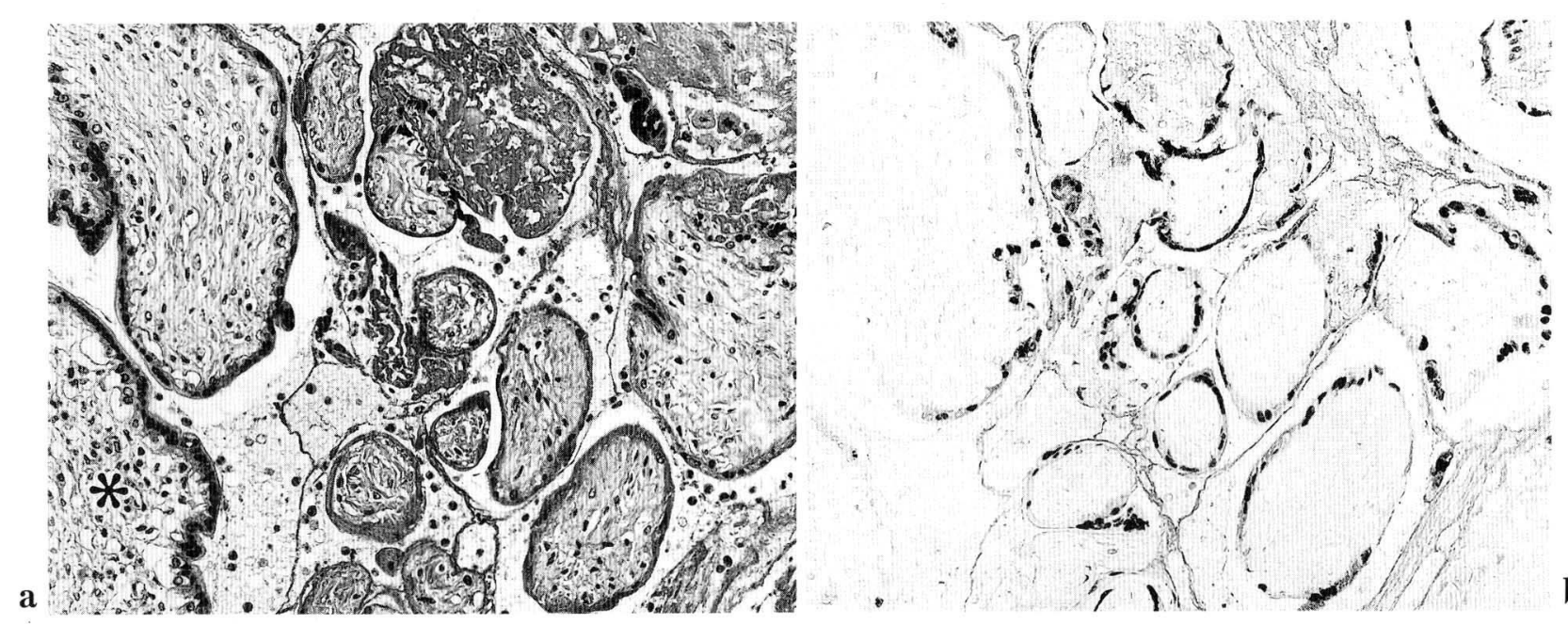

Fig. $4 \mathbf{a}$ and b. Strong TUNEL labeling in non-molar chorionic villi with anemic infarction, seen in a case of partial hydatidiform mole (32-year-old female). Most trophoblastic cells show positivity. Fibrinous exudation and neutrophilic reaction are noted. Asterisk demonstrates an intact villus at the periphery of infarction. a: Hematoxylin and eosin staining, b: TUNEL method. a, b: $\times 150$

\section{DISCUSSION}

The TUNEL method is able to label the $3^{\prime}-\mathrm{OH}$ end of double stranded DNA breaks in the apoptotic cells in routinely prepared paraffin sections (GAVRIELI et al., 1992). In fact, apoptotic bodies in the desquamating endometrial tissues (menstruation, functional bleeding or cancer) showed specific signals. The sensitivity of the method in paraffin sections did not appear to be significantly different from that using frozen sections.
It has been reported that apoptosis plays an essential role in controlling the physiological cell kinetics in the female reproductive organs and tissues, such as the endometrium (HOPWOOD and LEVISON, 1976; ROTELLO et al., 1989; GOMPEL et al., 1994), ovarian follicles (TilLy et al., 1991), and the regressing decidua (Gu et al., 1994).

In contrast, the present analysis targeting the chorionic villi demonstrated: 1) focal labeling of syncytiotrophoblasts with pyknotic nuclei and densely eosinophilic cytoplasm in the early stage of gestation, hydatidiform mole or in the term placenta; 2) labeling of 
pyknotic stromal cells in the early stage placental villi with marked hydropic degeneration or in molar villi; and 3) diffuse and dense labeling in foci of necrosis or infarction in the early, molar or term placenta. When compared with the hematoxylin and eosin stained preparations, cytologic features of the so-called apoptotic bodies were not discernible at these sites. Degenerative changes and fibrinous exudations were also recognized in conditions 1 ) and 3). These findings strongly suggest that the TUNEL sequence labels not only the apoptotic cells but also necrotic cells or degenerative cells in ischemic lesions.

The labeling of necrotic cells by the TUNEL method has already been pointed out in a detailed experimental study by GoLD et al. (1994), but they emphasized the usefulness of the method for the detection of apoptotic cells, in combination with the in situ nick translation technique using DNA polymerase I. Our emphasis is on precautions for the pitfalls of this histochemical technique, particularly when archival human pathological tissues are employed. The possibility of necrosis or ischemia should be carefully ruled out in any case. A brief description on the syncytiotrophoblastic labeling in the early and term placentas was recently presented by a Japanese group, but they regarded the positivity as apoptosis without comparing it with cytological changes (SAKURAGI et al., 1994). Moreover, it should also be considered that autolysis or postmortem change may accelerate DNA fragmentation, and the velocity of autolytic DNA ladder formation differs from tissue to tissue (IsHIBUCHI et al., 1991). Appropriate handling is essential for application of this histochemical technique and evaluation of the results.

We recently described sporadic p53 protein (over)expression in syncytiotrophoblastic cells in the paraffinembedded early gestational placenta and hydatidiform mole (YASUDA et al., 1995). p53 protein is known to play a critical regulatory role in apoptotic cell death (RYAN et al., 1993). It is possible that the TUNEL technique, useful screening histochemistry for apoptosis, can detect an apoptotic process within lesions which have classically been regarded as necrosis. In this sense, further detailed evaluation for possible apoptosis must be sought in conditions 1) and 2).

\section{REFERENCES}

Ansari, B., P. J. Coates, B. D. Greenstein and P. A. HALL: In situ end-labelling detects DNA strand breaks in apoptosis and other physiological and pathological states. J. Pathol. 170: 1-8 (1993).
Buja, L. M., M. L. Eigenbrodt and E. H. Eigenbrodt: Apoptosis and necrosis. Arch. Pathol. Lab. Med. 117: 1208-1214 (1993).

Carson, D. A. and J. M. Ribeiro: Apoptosis and disease. Lancet 341: 1251-1254 (1993).

Gavrieli, Y., Y. Sherman and S. A. Ben-Sasson: Identification of programmed cell death in situ via specific labeling of nuclear DNA fragmentation. J. Cell Biol. 119: 493-501 (1992).

Gold, R., M. Schmied, G. Giegerich, H. BReitschopf, H. P. Hartung, K. V. Toyka and H. Lassmann: Differentiation between cellular apoptosis and necrosis by the combined use of in situ tailing and nick translation technique. Lab. Invest. 71: 221-225 (1994).

Gompel, A., J. C. Sabourin, A. Martin, H. Yaneva, J. Audouin, Y. Decroix and P. Poitout: Bcl-2 expression in normal endometrium during the menstrual cycle. Amer. J. Pathol. 144: 1195-1202 (1994).

Gorczyca, W., J. Gong and Z. DARZYnkiewicz: Detection of DNA strand breaks in individual apoptotic cells by the in situ terminal deoxynucleotidyl transferase and nick translation assays. Cancer Res. 53: 1945-1951 (1993).

Gu, Y., G. M. Jow, B. C. Moulton, C. LeE, J. A. Sensibar, 0.-K. Park-Sarge, T. J. Chen and G. GIBORI: Apoptosis in decidual tissue regression and reorganization. Endocrinology 135: 1272-1279 (1994).

Hopwood, D., D. A. Levison: Atrophy and apoptosis in the cyclical human endometrium. J. Pathol. 119: 159-166 (1976).

Ishibuchi, T., Y. Hoshina, T. SAIto and T. MoriUchi: Organ DNA bank for the research in pathology (In Japanese). Byori-to-Rinsho 9: 1467-1471 (1991).

Kasagi, N., Y. Gomyo, H. Shirai, S. Tsujitani and H. ITo: Apoptotic cell death in human gastric carcinoma: Analysis by terminal deoxynucleotidyl transferasemediated dUTP-biotin nick end labeling. Japan. J. Cancer Res. 85: 939-945 (1994).

Kerr, J. F. R., A. H. Wyllie and A. R. Currie: Apoptosis: A basic biological phenomenon with wide-ranging implications in tissue kinetics. Brit. J. Cancer 26: 239257 (1972).

Rotello, R. J., M. B. Hocker and L. E. Gerschenson: Biochemical evidence for programmed cell death in rabbit uterine epithelium. Amer. J. Pathol. 134: 491-495 (1989).

Ryan, J. J., R. Danish, C. A. Gottlieb and M. F. Clarke: Cell cycle enalysis of p53-induced cell death in murine erythroleukemia cells. Mol. Cell. Biol. 13: 711719 (1993).

Sakuragi, N., H. Ishikura, H. Hareyama, N. Takeda, K. Hirahatake, T. OHKouchi, M.-L. Luo, N. Tsumura, S. Makinoda and S. Fujimoto: Apoptosis in human trophoblastic cells identified by in situ nick end labeling of fragmented DNA (In Japanese). Nippon Sanka Fujinka Gakkai Zasshi 46: 533-534 (1994).

Tilly, J. L., K. I. Kowalski, A. L. Johnson and A. J. W. HsUEH : Involvement of apoptosis in ovarian follicular atresia and postovulatory regression. Endocrinology 129: 2799-2801 (1991). 
Williams, G. T. and C. A. Smith: Molecular regulation of apoptosis: Genetic control on cell death. Cell 74: 777779 (1993).

Yasuda, M., K. Kawai, H. Serizawa and R. Y. Osamura: Immunohistochemical analysis of expression of p53 protein in normal placentas and trophoblastic diseases. Appl. Immunohistochem. (1995, in press).
Dr. Yutaka TsuTsumi

Department of Pathology

Tokai University School of Medicine Bohseidai, Isehara, Kanagawa 259-11, Japan

\section{堤寛 \\ 259-11 伊勢原市望星台 \\ 東海大学医学部}

病態診断系病理学部門 